\title{
Introduction of Information Business Course in the Content of the Computer Science Program
}

\author{
Alzhanov I. A. ${ }^{1}$, Ismagambetova F. A. ${ }^{2}$, Abildinova G. M. ${ }^{3}$, Mubarakov A. M. ${ }^{4}$, Alzhanov A. K. ${ }^{5}$ \\ ${ }^{1}$ PhD student, Master of Pedagogic sciences, Computer Science department, L.N. Gumilyov Eurasian National University, \\ Satpayev Str., 2, 010008, Nur-Sultan, Republic of Kazakhstan; \\ ${ }^{2}$ PhD student, Master of Arts in Economics, Computer Science department, L.N. Gumilyov Eurasian National University, \\ Satpayev Str., 2, 010008, Nur-Sultan, Republic of Kazakhstan;
}

${ }^{3}$ PhD, Associate Professor, Computer Science department, L.N. Gumilyov Eurasian National University, Satpayev Str., 2, 010008, Nur-Sultan, Republic of Kazakhstan;

${ }^{4}$ Doctor of Pedagogic Sciences, Professor, Computer Science department, L.N. Gumilyov Eurasian National University, Satpayev Str., 2, 010008, Nur-Sultan, Republic of Kazakhstan;

${ }^{5}$ Candidate of Pedagogic Sciences, Head of Department, Computer Science department, L.N. Gumilyov Eurasian National University, Satpayev Str., 2, 010008, Nur-Sultan, Republic of Kazakhstan

\begin{abstract}
In today's rapidly changing world of innovative technologies, it is necessary to search for means of modernization of educational process, where along with implementation and constant improvement of new technologies and software it is also important to update the content of education system as well. The modern and developing education institution requires experts in the various related fields. First, it is necessary to know the modern innovative technologies; second, to employ these technologies in various sectors and activities. With regard to the above, the content of education programs with respect to the development of the promising areas should be revised these days. The given article analyses the development of educational content in computer science of Kazakhstan, determines the theoretical basis, development and practical realization of introducing the content of computer science in secondary school. The authors of this article introduced information business in the course of computer science with an aim to develop the content of computer science discipline by introducing elements of information business. The content and structure of training in the fundamentals of information business was introduced in the educational process as a separate elective course and as a fragment of general education computer science course.
\end{abstract}

Keywords: computer science training, information technologies, information business, course structure, information model, methodological approach.

\section{INTRODUCTION}

In the State Program "Digital Kazakhstan" it was stated that digital revolution transforms the present-day methods of production, the main focus should be put on the sector of information business. Digitalization of interaction of the State and business is aimed at reduction of transaction costs of entrepreneurs, contributing to the enhanced transparency of decision taken by government authorities and organizations [18].
Along with improvement and cheapening of information technology, it has penetrated into different industries and made it possible to improve the efficiency of the latter. As a result of the development of information technologies, new needs of society have emerged. The role of IT in the economic activity of many enterprises is changing. When performing intra-company processes, IT function is not auxiliary, but is an essential part of the product or production capacity. Economic risks are now largely determined by the risks in this area. The implementation of modern high-performance organizational projects requires the full use of IT potential with the help of telecommunications. The use of IT is designed to neutralize the organizational complexity of an enterprise. Previously, this was achieved through the use of computers for complex calculations and processing of documentation in quite large volumes. Now it is important that the increasingly complex horizontal and vertical models of relationships (which structures, in turn, are constantly changing) should be improved by means of new communication technology.

In modern society, information technology is a universal tool in the management of organizations of all types that operate in all spheres. The central functions of modern information technologies of enterprise management are collection, storage, search, systematization and processing of the necessary data for all spheres of public life, generation of new information, solution of various optimization problems. The task is not only to select and automate labor-intensive, regularly repeated routine operations on large amounts of data, but also to obtain fundamentally new information that is necessary for effective management decisions.

The last information revolution gave a boost to such significant changes in the development of society that a new term "information society" appeared to characterize it. Information technologies make it possible to optimize and automate information processes, which occupy an increasingly important place in the life of society. There is a stage of formation of information society, for which not the material values, but information and scientific knowledge 
become objects and results of work of the majority of the employed population. In developed countries, the majority of the employed population is more or less involved in the generation, storage, processing and transfer of information, and therefore has to learn and make practical use of the information technologies that are relevant to these processes. Information technologies play a key role in the acquisition and accumulation of new knowledge. Traditional methods of information support of scientific research (accumulation, classification and dissemination of scientific and technical information) are replaced by new ones that are based on the use of newly emerging opportunities of information support of fundamental and applied science. Modern information technologies are based on the theory of artificial intelligence, methods of information modeling, cognitive computer graphics, allowing to find solutions to poorly formalized problems, as well as problems with incomplete information and unclear source data.

Informatization of society is a global social process, which is characterized by that the dominant type of activity in the field of social production is the collection, accumulation, production, processing, storage, transmission and use of information, performed on the basis of modern means of computer technology, as well as on the basis of various means of information exchange. The concept of information is fundamental in this process. Any human activity is the process of collecting and processing information, making decisions built upon it and their implementation. With the advent of modern computer technology, information has become one of the most important resources of scientific and technological advancement.

A certain stage of development of the information industry generates an information society, where the majority of workers are engaged in the production, storage, processing and use of information, i.e. creative work aimed at the development of intelligence and knowledge. A single information community of people, not divided by national borders, is being created.

The transition from industrial to information society is manifested in the following:

- increasing redistribution of labor resources from the sphere of material production to the sphere of information services [24];

metal or paper money is replaced by electronic information, substituting traditional forms of payment with electronic payment systems, ecommerce, etc.;

Informatization covers all socially important areas of human life: economy, politics, culture, etc [25].

Turning to the infrastructure of the information industry, it should be noted that the sector of information business is very extensive and includes various activities that are directly or indirectly related to information. At the same time, there is a constant change and increase in infrastructure.

The development of global information resources has allowed:

To make the activity of providing information services in global human activity;
- $\quad$ To form the world and state market of information services;

- To form various databases of resources of regions and states, which are available for relatively inexpensive access;

To improve the validity of and time spent on decision-making in firms, banks, stock exchanges, industry, trade etc. due to timely use of the necessary information.

The information infrastructure consists of three part: preserved information flows from the old-type organizations, new information flows of market structures, shadow information flows. In solving many market problems, enterprises have to use information from different streams, which is not always easily accessible. But none of the flows is a full-fledged resource for information support of the society's development. There are only individual products, local information systems, numerous websites, which often have unverified information. This significantly complicates the formation of a single information system of an enterprise that can provide effective assistance in business management.

The success of the business involved in the processing of a variety of digital information flows depends not so much on technology, but on the proper combination of organizational elements, business practices and related tools.

One of the most studied areas of activity that is easy to automate is the paperwork and document management in the enterprise. The modern system of automation of document flow allows to integrate the technology of office organization in a single process, to ensure the joint and coordinated use of automated collection, processing, storage and transmission of information presented in any form (text, graphics, audio, video).

Information technologies are designed to optimize the process of collection, storage and processing of information, reduce the complexity of the use of information resources, improve the validity of management decisions through the integration and timely update of information, the use of new forms of information support for all activities. In recent years, a very popular area that emerged at the intersection of management and computer science, is the business processes reengineering i.e. fundamental rethinking and redesigning of business processes of the organization in order to significantly improve the most important indicators of its activities. Such process is unfeasible without the widespread use of modern information and computer technologies. Systems that are oriented towards re-engineering should include all of its stages:

- strategic planning, i.e. identification of the purpose of the enterprise, its goals and objectives, performance indicators;

- description of the business architecture of the organization (identification of the main business processes, relationships that arise between structural units and employees in the process of their implementation);

- functional modeling of business processes.

As was noted in the work of Gayurov and Vokhidova (2013), in the process of informatization of society, one of the most 
important tasks is the training of specialists with higher education, who know well not only the subject area, but also the already used, as well as promising information technologies related to their professional activities.

The process of developing a specialist, and education of the latter is inextricably linked with the professional orientation of the educational process, according to Baranova and colleagues (2010). An integrated approach to learning, mastering of the material is quite often declared, but is implemented neither in educational programs nor in practical professional activities, because people are not always accustomed to see and evaluate the links, to look for their full set, to determine the integrity of the phenomena, i.e. to separate external links from internal ones, essential from non-essential, permanent from temporary, main from secondary, etc. This is a question of systemic thinking, which is formed in the educational process, and better formed when the links are presented in the schemes very specifically, clearly, when they are highlighted and shown, differentiated by criteria, when the text gives an explanation of these links [1].

Innovative processes aimed at changing the educational paradigm affect the essence of the concept of information culture. The construction of technology of teaching informatics that is corresponding to modern trends is particularly urgent. Such technology should be aimed at the formation of information culture of students of higher educational institutions [3].

According to Kirillova (2014), there is a need to develop and use non-traditional technologies and teaching methods based on modern computer technology with the implementation of active learning methods. These methods are supposed to activate the entire learning process, as well as contribute to the identification of systems and means to increase the activity of students through motivation for educational and cognitive activity.

Year to year innovative educational activity becomes more and more widespread. There is a growing need to significantly update the content of education, and this is implemented in numerous innovative initiatives. Innovative educational activity is the activity which facilitates the development of the educational process (whereas traditional educational activity is the activity through which the stability of the educational process is ensured) [15].

Kolchina (2017) believes, that training of managers of a new type with economic thinking, mobility and ability to effectively carry out the innovative and entrepreneurial activity, which is based on a sufficient level of formation of innovative and entrepreneurial competence, becomes an integral task of modern education.

The variety of concepts and practical approaches to the management of modernization of education, based on innovation, stems from the significant differences in the organizational structures of education systems, their legal framework, as well as the established traditions and the current paradigm of economic management in each country. At the same time, in this issue overall trends are clearly visible, where the main ones are decentralization and democratization of management, expansion of autonomy of higher education institutions with simultaneous strengthening of their involvement in solving the problems of socioeconomic development of society, movement towards integration of market models of management and financing of the educational process into the higher education system. In other words, the scientific and educational sphere as a socioeconomic system, performing its specific functions in the economy (which can be differentiated into two large groups: educational and scientific-innovative), is a special sector that "provides" economic development as the whole, which is generated by new knowledge accumulated in human potential, and innovations focused on commercialization or the creation of fundamental scientific potential of the country [11].

The use of new information technologies allows making the processes of organization and planning several times faster, and the development of management methods using accelerated information flows or virtual methods of organization and management reduces not only the time for decision-making, but also their efficiency. Modern management is a set of actions selected on the basis of a certain information processing technology aimed at optimization and development of the processes of functioning of the production system to achieve the set goals [17].

During the training of students in informatics, the primary objective is the analysis of the content of disciplines for compliance with educational standards with the prospect of wide application of the received knowledge in future professional activities (including in the fast-changing requirements for specialist), i.e. the demand of knowledge obtained [20].

As stated Helfert in his work (2011): "It seems that the information systems curriculum should include many (if not all) related subjects ranging from business and information system strategy to management and marketing, organizational concepts, modelling and information systems architecture, programming, mathematics, statistics and operations research as well as computing, networking and Information and Communication Technologies (ICT)."

Karyakin and Savelyeva (2011) believe, that the peculiar feature of Informatics as a science and field of application of practical knowledge is that it has very high dynamics of its development. What was advanced and sufficient for labor activity yesterday, today becomes quite outdated. The high dynamics of IT development requires rejection of great static in the construction of curricula and plans, requires greater freedom of universities to form curricula and programs. The competitiveness of universities and departments that produce specialists in computer science and data processing will be determined by their ability to build curricula and programs that do not lag behind the development of methods and means of data processing and the ability to fill them with real modern content.

The purpose of this study is to describe the current state on the theory and practice in the field of the educational process, to reveal the tendencies of development of training of computer sciences, to implement information business course into the educational program of the universities of Kazakhstan. In 
educational programs on the computer sciences, a significant part of the courses is allotted for the programming. The content of Kazakhstan's educational programs includes training in unpopular programming languages (logic programming) [9], Prolog for example, as well as training in languages that aim to enhance the productivity of the programmer, rather than the code itself, like Python. At the same time, the teaching practice and trends in the society's development set the terms not for a unilateral training, but for the development of the IT sector through its introduction into the various areas, such as business and economics. In the content of students training programs that are focused on the computer sciences it is necessary to expand the practical aspects of courses introduction [14]. In modern education, where joint degree programs are developing in a rapid pace, the necessity of such expansion of practical aspects should be considered. One of the priority areas is the building the competence of development of business-processes, introduction of courses that focus at the building start-up projects that are aimed at active marketing and possible further establishment of entrepreneurial, independent, private universities.

In the modern educational program of Kazakhstan's universities, the component of basic and major elective subjects has increased from $67 \%$ to $70 \%$ for Master's degree program and from $80 \%$ to $95 \%$ for Doctoral program. For example, the educational program of the Master's degree $6 \mathrm{M} 011100$ - Computer sciences - 49 credit hours of theoretical training are provided, where 33 credit hours from this amount are the elective components focused on the mastering practical skills in the field of IT and related disciplines. In the educational program we introduced the elective course on information business for identification the efficiency of training of future specialists and formation of competences, which they might apply in their professional activities. The main objective of this study is the possibility to train students to manage IT projects, formation of business model on digital markets, enterprise content management, decision-making on the design and implementation of information systems.

\section{MATERIALS AND METHODS}

The aim of this article is the analysis of development of educational content in computer science of Kazakhstan, determination of theoretical basis, development and practical realization of introducing the content of computer science in secondary school. During this study there were used methods of pedagogical studies, such as study analysis on theme, methods of theoretical comparison and generalization, studying international experience, questioning. The authors of this article introduced information business content in the course of computer science with aim to develop the content of computer science studies by introducing elements of information business. The content and structure of training in the fundamentals of information business was introduced in the educational process as a separate elective course and as a fragment of general education computer science course. Practical significance of this study consists in the development of the elective course "Fundamentals of information and digital business" and the corresponding theme in the computer science course.

\section{RESULTS AND DISCUSSION}

Computer science in a broad sense is a unity of various branches of science, technology and production associated with the processing of information mainly through computers and telecommunications in all spheres of human activity. The specificity and importance of computer science as a branch of production is that it largely depends on the growth of labor productivity in other sectors of the economy. Moreover, for the adequate development of these industries, labor productivity in computer science itself must growth at a higher rate, since in modern society, information more and more acts as an object of final consumption: people need information about events happening around the world, about objects and phenomena related to their professional activities, about the development of science and society itself. Further growth of labor productivity and welfare is possible only on the basis of the use of new intellectual means and humanmachine interfaces focused on the reception and processing of large amounts of multimedia information.

Computer science does not exist by itself, but is a complex scientific and technical discipline designed to create new information technologies to solve problems in various fields. It provides methods and tools to study other areas, even those where it is considered impossible to apply quantitative methods due to non-formalized nature of processes and phenomena. In computer science, particular attention should be paid to the methods of mathematical modeling and methods of image recognition, which practical realization became possible due to achievements of computer equipment.

The main function of computer science is to develop methods and means of information transformation and their use in the organization of the technological process of information processing.

Today, one of the most important factors of competitiveness is the use of modern information technologies in enterprise management; the successful performance of many activities is impossible without these technologies. Therefore, their effective use has become a decisive factor in the success of enterprises in the market. The development of information computer technologies, improvement of the technical platform and the emergence of fundamentally new classes of software has led to a change in approaches to the automation of production management [22].

As stated Degtyareva and Semenyachenko (2016), specialists in the field of business informatics should have such professional competencies as the ability to use the appropriate mathematical apparatus and tools for processing, analysis and systematization of information, the ability to conduct research and analysis of the market of information systems and information and communication technologies.

The market requires truly practice-oriented specialists, combining theoretical and practical knowledge of economics, 
marketing, management and information technology. The quality implementation of the required educational standards in the training of business informatics is possible to achieve primarily through the integration of disciplines responsible for a certain enlarged training module. For example, the integration of disciplines such as mathematics, computer science and marketing enables to get a specialist that meets the modern requirements of the market, especially in the issues of analytical support in decision-making in business management.

One rapidly developing IT sector is marketing. Automation of information processes in the field of marketing is an extremely important competitive advantage. The automated marketing system, as a rule, includes a number of subsystems designed to ensure the making of marketing decisions by the top management of the company and conducting marketing research. As well as traditional commerce in modern conditions is unthinkable without the active use of IT. First of all, the distributive sphere becomes automated, in the relationships between trade organizations and buyers, the Internet is widely used and helps to automate the control over the goods movement, to monitor the market. Business entities using the Internet have direct access to new markets and the possibility of expanding sales networks.

According to Chirkov (2013), for the professional level of information culture of an individual, knowledge and skills are characterized by specificity, greater complexity, but at the same time, by limited scope of application. "They will be connected to the professional activity of a person, and when studying at the university - to the disciplines that form its foundations" - as stated Sen (2011).

The world's leading countries have achieved success in the field of scientific and technological advancement through the intensive development of education, science and technology. The success of science-intensive production, technical and social progress are increasingly determined by the qualitative characteristics of the national education system, the adequacy of training of scientists and highly qualified specialists for the requirements of the emerging neoeconomics. In the context of globalization, only countries that have a highly effective education system that meets the modern requirements of innovative economic development can be among the developed countries of the modern world. In almost all developing countries that demonstrate high rates of economic growth, the priority areas of state support are education and improvement of literacy, training of highly qualified specialists, development of science-intensive industries based on high technologies.

Modernization of the education system on the basis of innovation is impossible without a preliminary definition of the main priorities of the state economic policy, which set the main direction of the vector affecting the educational environment. There is no doubt that the scientific and educational sphere in general and higher education in particular, because of their special position in society, are not so much the purpose of innovation, as a condition for sustainable innovative development of the economy of any country.
Modern society is in need of specialized educational programs and training of qualified personnel in the field of information management, information business analytics and information systems (Business Software Applications Specialist), having a comprehensive, adequately formed knowledge in the field of economics, management and law, possessing the theoretical foundations and practical skills of business process management, analytical support of decision-making, conceptual design of corporate information systems, management of design and implementation of information systems. It is the synthesis of knowledge at the intersection of different subject areas that determines the proper connection of the concepts of "business" and "informatics" in the name of a new educational direction "business informatics" [26].

The concept of contextual learning in training future professionals occupies a special place. The implementation of contextual learning technologies [23] in the educational process of a modern university implies that knowledge is acquired by students in the context of solving the simulated educational and professional situations, which determines the development of professional motivation and professional thinking of the future specialist, personal senses of the learning process, according to Nikitina and Romanova (2013). The meaningful foundation of the contextual learning technology, as above authors state, consists of the following types of problem situations (quasiprofessional): the intellectual situations (include information about the cognitive nature of future professional activity, about the principle of the functional responsibilities of a specialist about the requirements for professionally important qualities and competencies of a specialist, etc., and also involve student's self-evaluation on the professional preparedness to work); emotional and personal situations (contribute to the formation of positive attitude to the future profession, awareness of the difficulties of adaptation to real working conditions); regulatory and behavioral situations (provide for choice of behavior model in specific business situations, enhance adaptive capacity of students).

Most of the trends and forecasts of the IT industry indicate the global expansion and growth of the share of information technologies in the life of modern society, and, therefore, the increasing need for young IT professionals who could solve new problems of creation, implementation, development, support, protection and automation of digital content, economic information systems [7].

The experience of other countries [2;4] demonstrates that the best solution of the above problems is to implement the course of information security in the educational program.

In article of McAdam and colleagues (2017) authors studied an active interaction with the industry and end users. For this purpose, they used the methodology that is based on the case studies of the two universities, and depicted a hybrid business model of the university technology transfer.

The content of the educational business course is aimed at preparation teachers in the field of entrepreneurship and information business, the development of entrepreneurial projects and projects in the field of entrepreneurship education. Thus, the development of the content of the course 
International Journal of Engineering Research and Technology. ISSN 0974-3154, Volume 13, Number 11 (2020), pp. 3761-3771

(C) International Research Publication House. https://dx.doi.org/10.37624/IJERT/13.11.2020.3761-3771

is primarily the development of its program, didactic and methodological support, a system of tasks for practice that provide effective training of students. To implement this course it is necessary to form the basic knowledge of the essentials of entrepreneurial activity.

To implement the practical part of the course of business analysis and data visualization in the educational program 5B011100 - Computer Sciences - there were introduced the results of Power BI Desktop that allow to analyze "live" data and create visual reports in the car industry of the Republic of
Kazakhstan with no involvement of IT specialists. The program enables presenting all the data of an enterprise on a single dashboard, analyzing heterogeneous information and turn it into expressive interactive reports that can be shared with other users. Among the advantages of the application is support for importing files of different formats, the possibility of mobile access, real-time data updates, etc.

To create a visual report, one must first import data from certain sources, in this case, we consider Excel file that comprises the necessary data (Fig. 1).

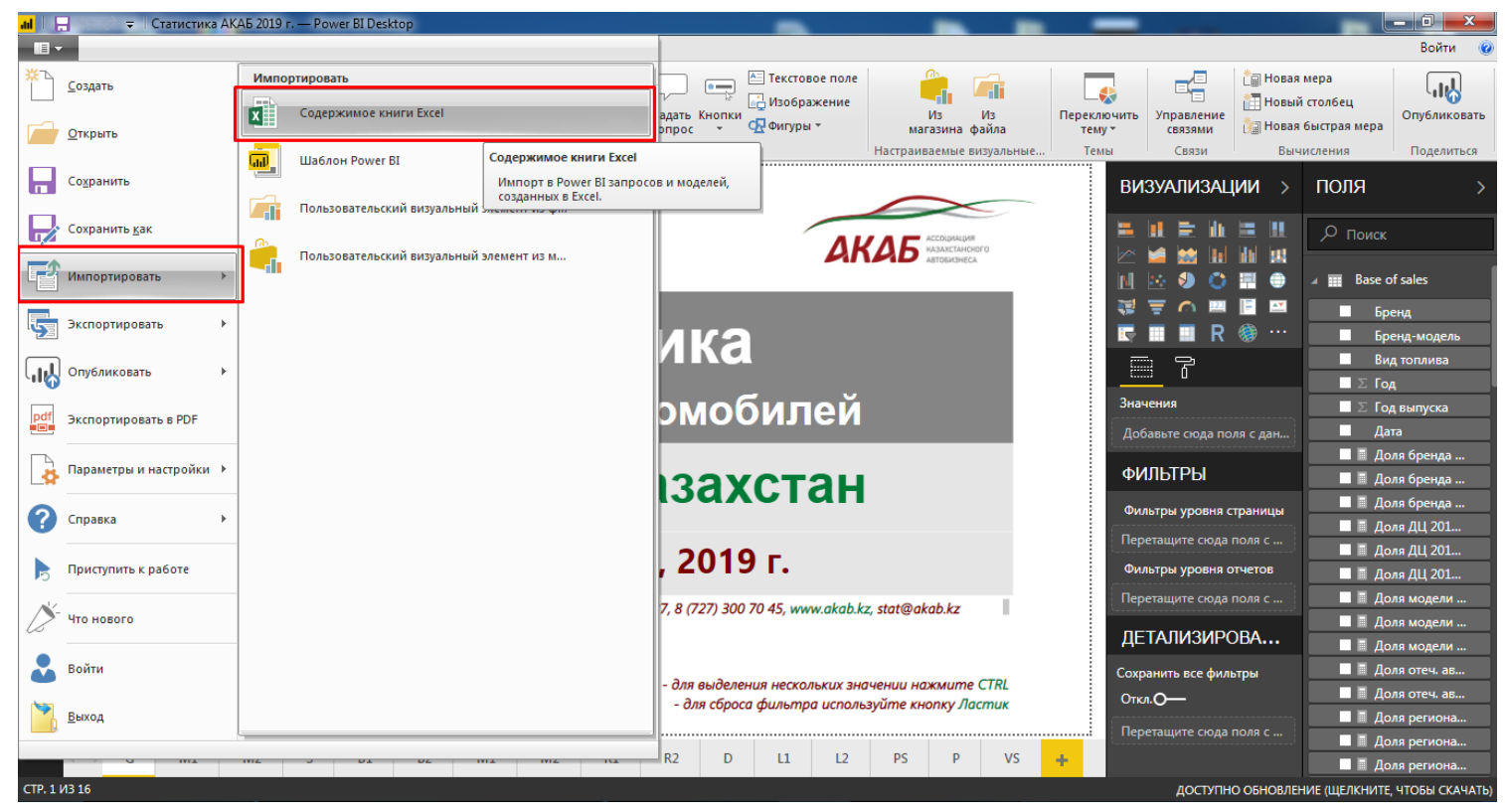

Fig. 1. Step 1 of the creation of a visual report on the specified data.

The program automatically determines the type of data by the values in the cells for further work with them. Car sales data were uploaded, with details for each car (Fig. 2).

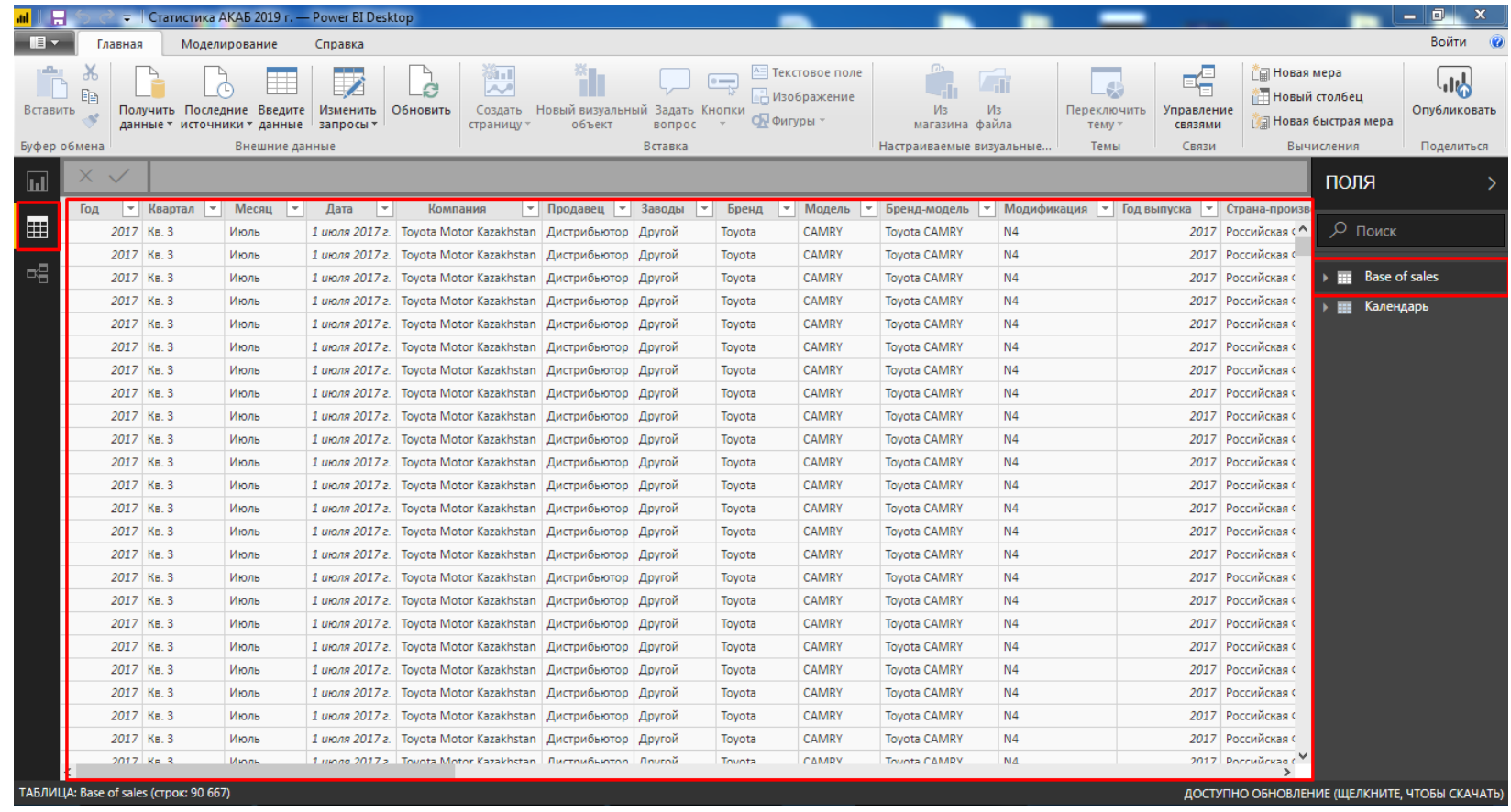

Fig. 2. Step 2 of the creation of a visual report on the specified data. 
International Journal of Engineering Research and Technology. ISSN 0974-3154, Volume 13, Number 11 (2020), pp. 3761-3771

(C) International Research Publication House. https://dx.doi.org/10.37624/IJERT/13.11.2020.3761-3771

When working with sales statistics, basically all reports are generated on a monthly basis, the figures are compared with the same period last year or last month. Therefore, in addition to the sales database, a second "Calendar" table is created, where corresponding month, quarter and year is specified for each date in the program (Fig. 3).

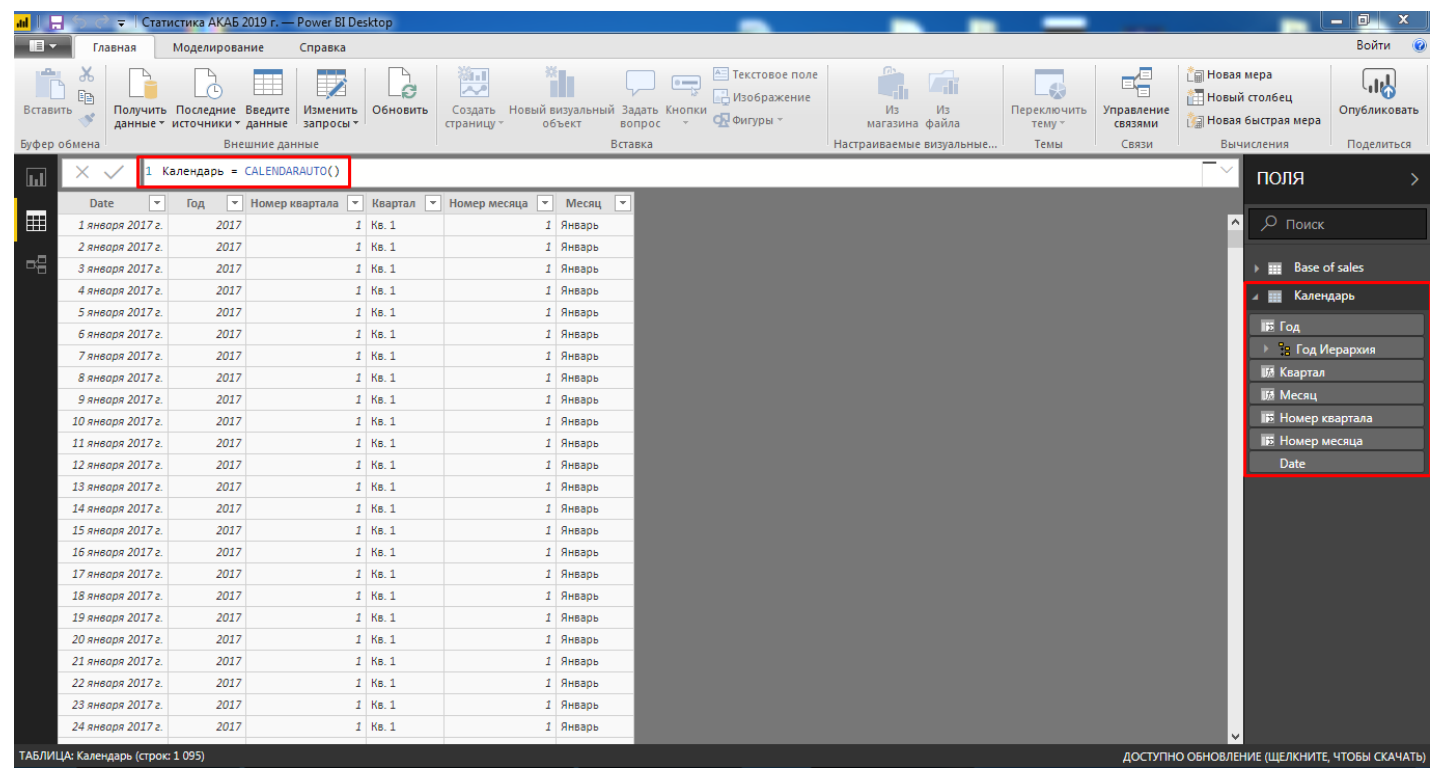

Fig. 3. Step 3 of the creation of a visual report on the specified data.

Then the date of the main database is linked with the "Calendar" table (Fig. 4).

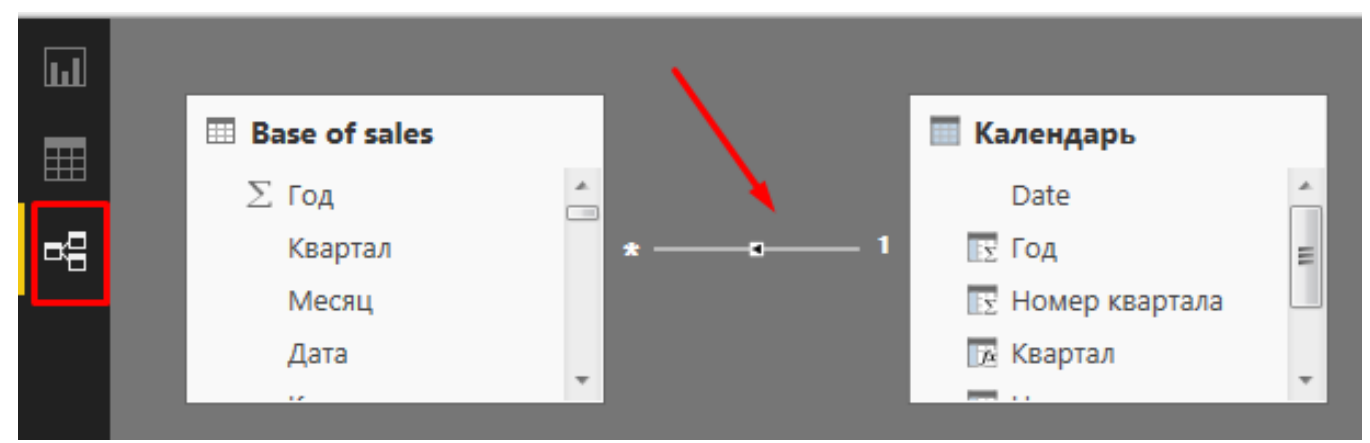

Fig. 4. Step 4 of the creation of a visual report on the specified data.

After filling in the data, the appropriate visual objects are then selected on the Dashboard to display the information. Then it is filled with the necessary data by using the columns of the main database (Fig. 5).

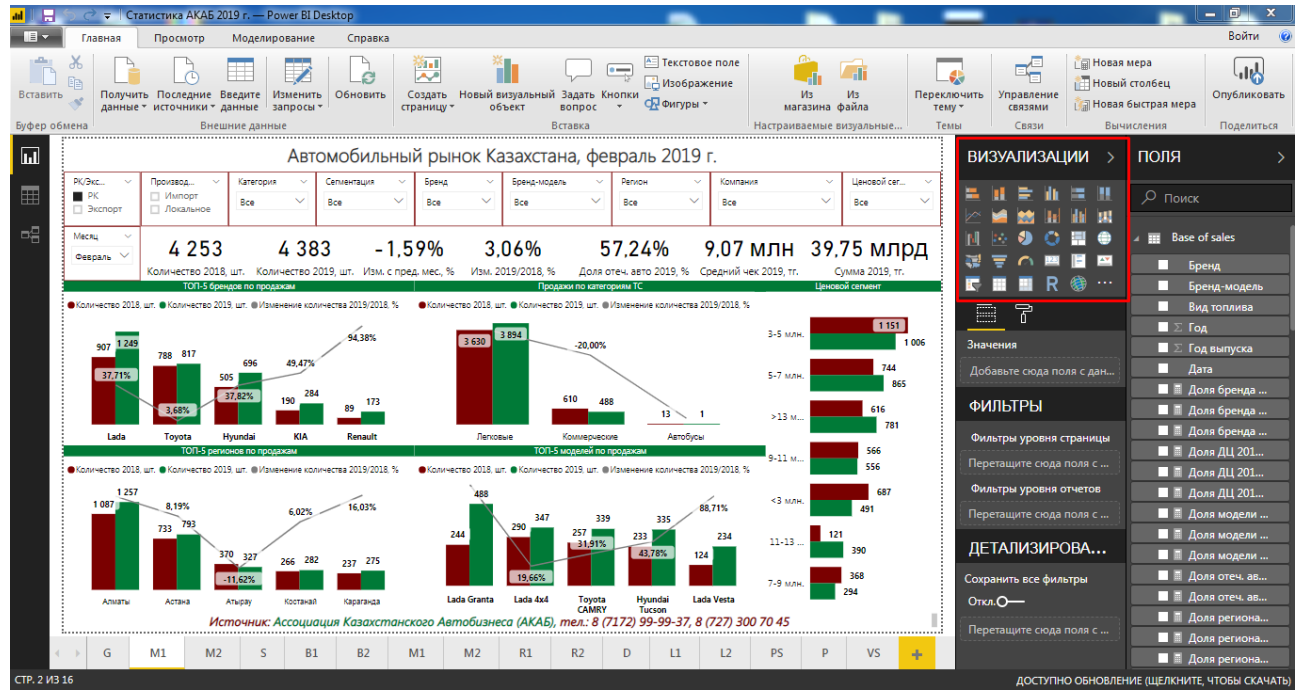

Fig. 5. Step 5 of the creation of a visual report on the specified data. 
International Journal of Engineering Research and Technology. ISSN 0974-3154, Volume 13, Number 11 (2020), pp. 3761-3771

(C) International Research Publication House. https://dx.doi.org/10.37624/IJERT/13.11.2020.3761-3771

It is also possible to create own formulas and filters by using the basic imported data (Fig. 6).

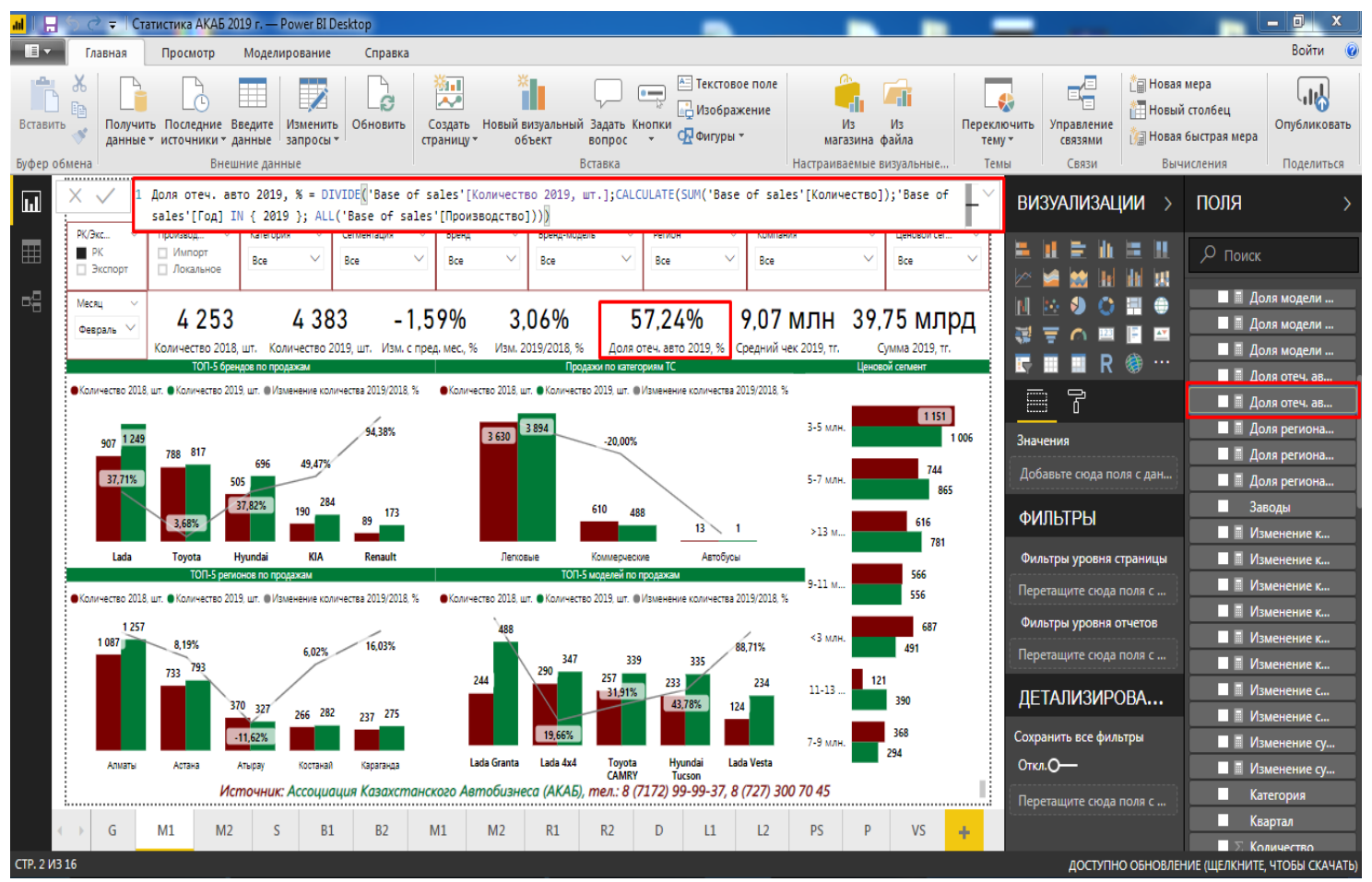

Fig. 6. Step 6 of the creation of a visual report on the specified data.

When working with big data, the information should be filtered by a certain value, for example, display the TOP 10 by the number of sales. In the filters, the filter on the top 10 sales by the total amount should be specified for this value (Fig. 7).

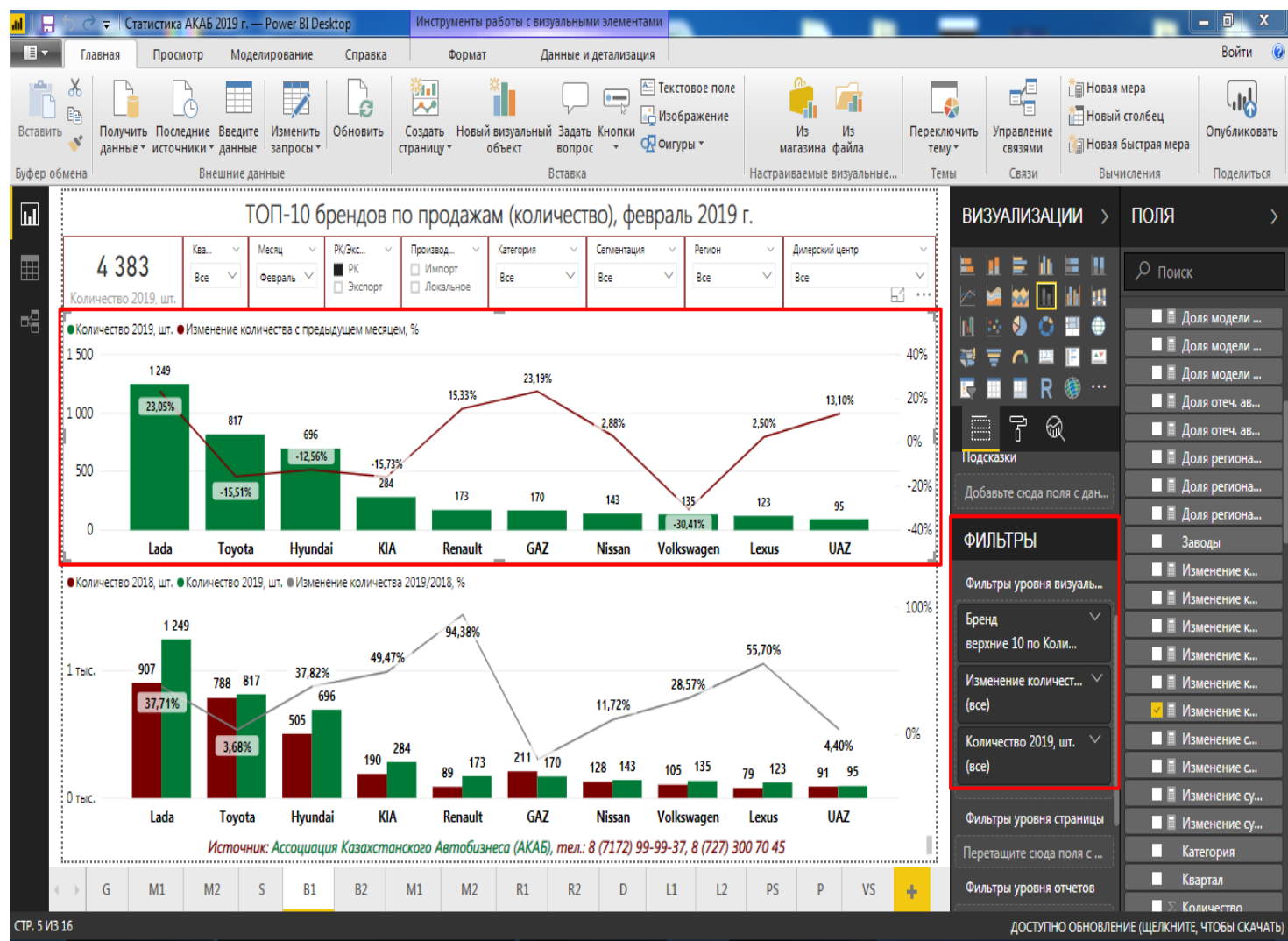

Fig. 7. Step 7 of the creation of a visual report on the specified data. 
International Journal of Engineering Research and Technology. ISSN 0974-3154, Volume 13, Number 11 (2020), pp. 3761-3771

(C) International Research Publication House. https://dx.doi.org/10.37624/IJERT/13.11.2020.3761-3771

The program is aimed to present data on a single dashboard, analyze heterogeneous information and turn it into expressive interactive reports (Fig. 8).

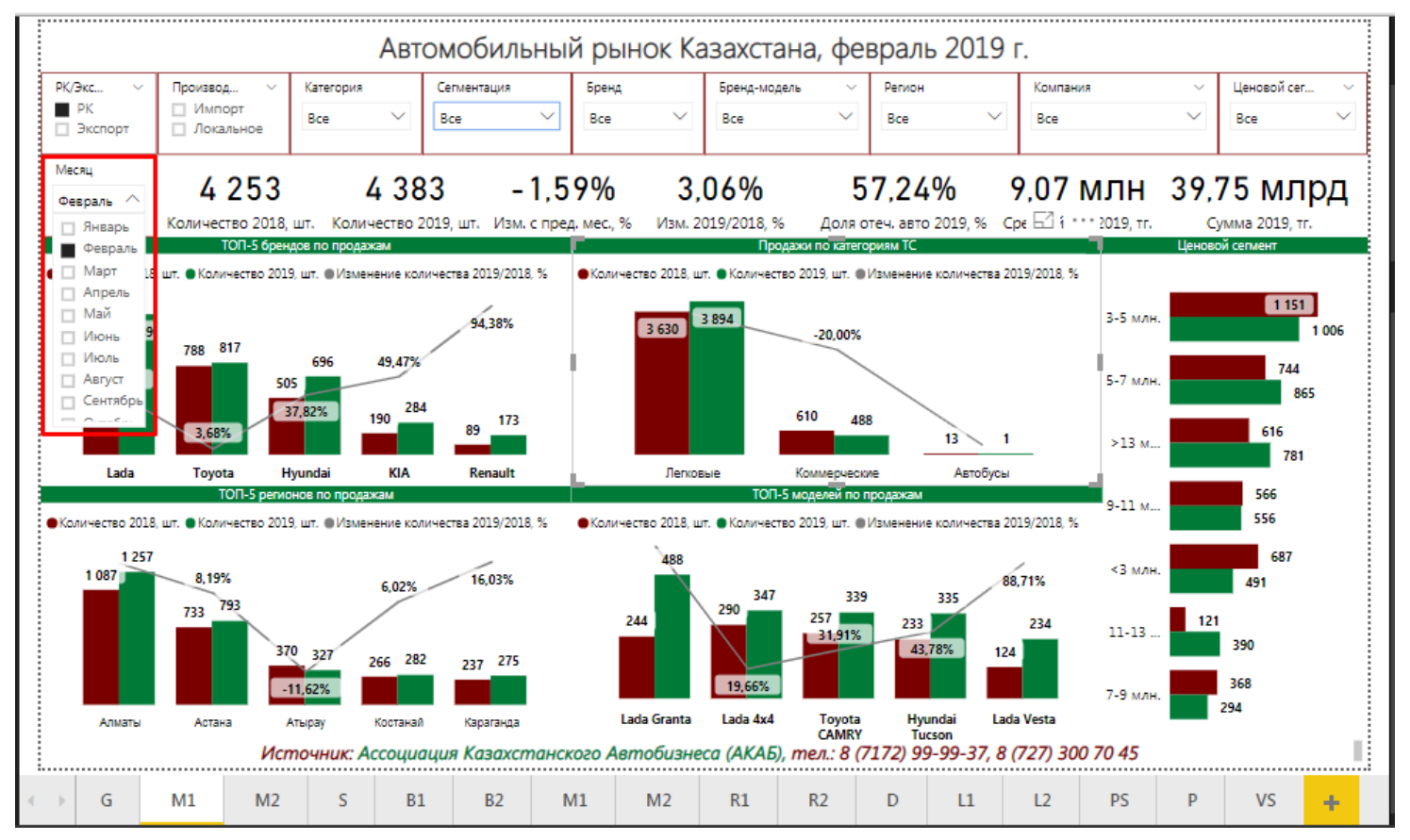

Fig. 8. Step 8 of the creation of a visual report on the specified data.

When the report is ready to be shared with others, it can be published in the Power BI service to make it public. Publishing a Power BI Desktop report is possible by clicking the "Publish" button (Fig. 9).

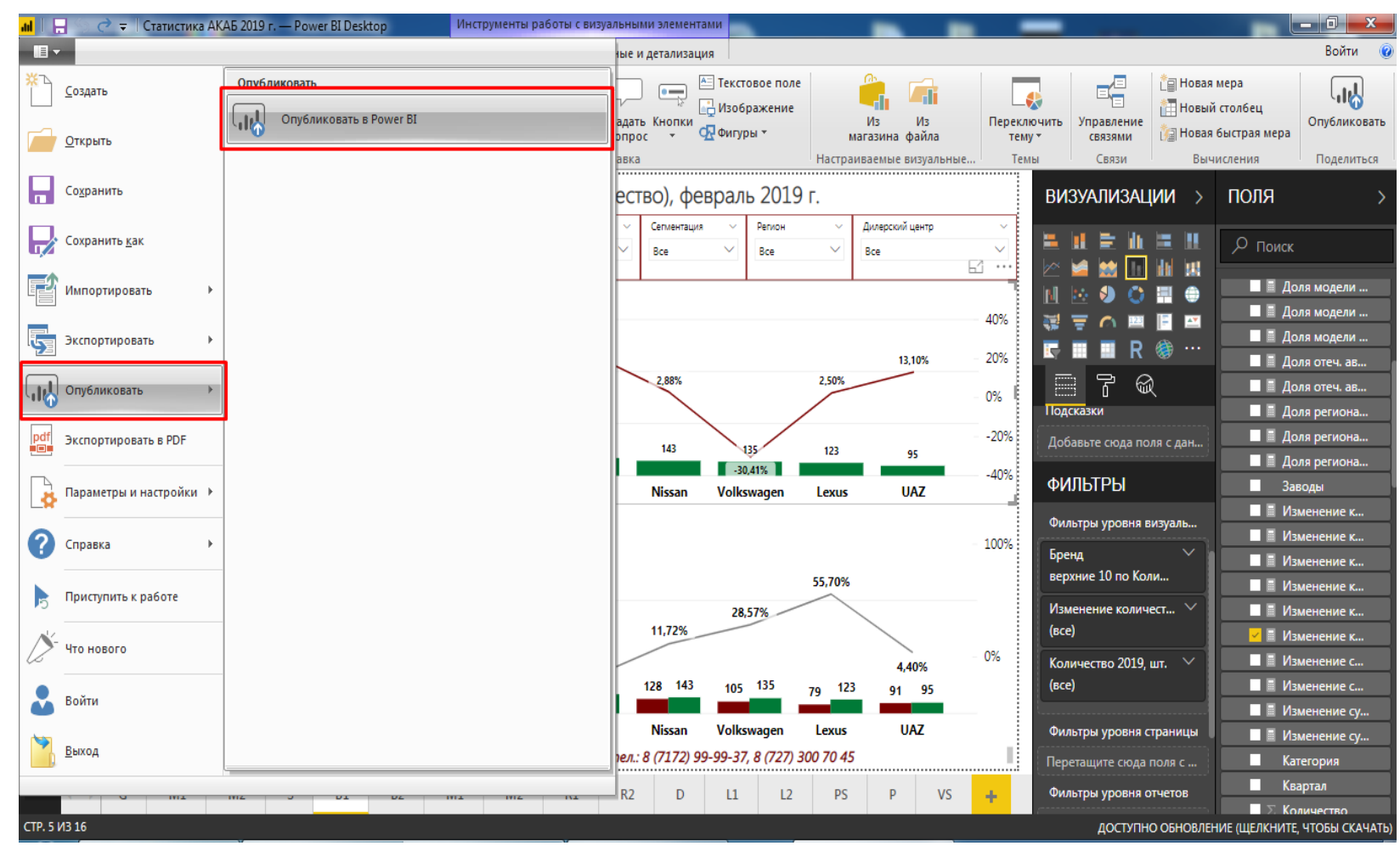

Fig. 9. Step 9 of the creation of a visual report on the specified data. 
By using Power BI "Publish on the Web" it is possible to get the link to share a report with other users (Fig. 10).

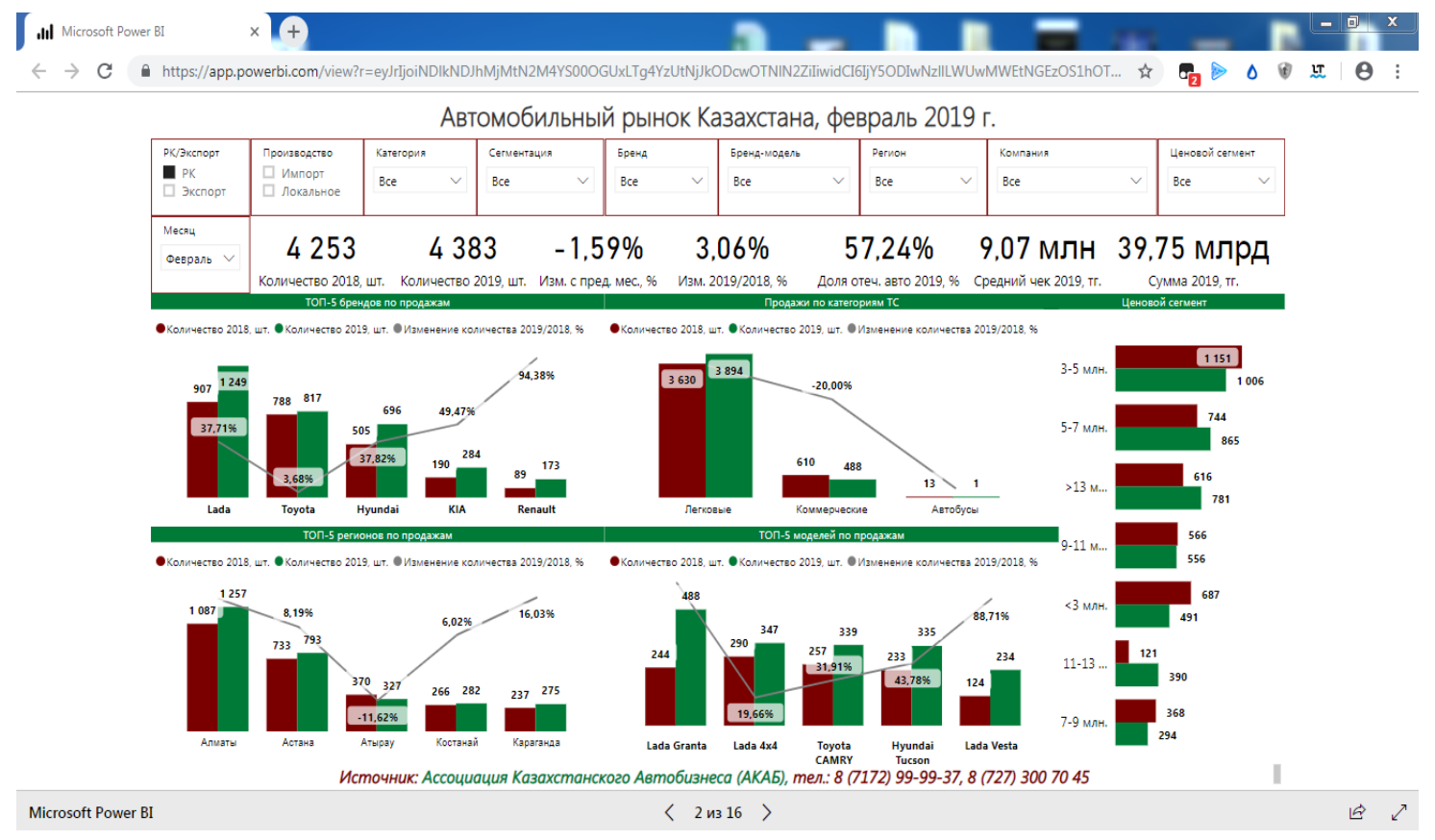

Fig. 10. Step 10 of the creation of a visual report on the specified data.

With the help of the created report it is possible to get visual information on the market of sales of new cars in the Republic of Kazakhstan on the following indicators:

- number and cost of sales;

- categories and segments of vehicles;

- brands and models;

- region;

- company;

- price segment;

- dates (month, quarter, year);

- dealerships;

- sales market (internal and external sales).

\section{CONCLUSION}

The conducted study aimed primarily at the introduction of information business course into the educational program of the universities of Kazakhstan, as well as at examining the current state of the theory and practice in the field of the educational process, and revealing the tendencies of development of training of computer sciences.

In the context of globalization, only countries that have a highly effective education system that meets the modern requirements of innovative economic development can be among the developed countries of the modern world. The market requires truly practice-oriented specialists, that have theoretical and practical knowledge of economics, marketing, management and information technology. The specificity and importance of computer science as a branch of production is that it largely depends on the growth of labor productivity in other sectors of the economy.

To implement the practical part of the course of business analysis and data visualization in the educational program, there were introduced the results of Power BI Desktop that allow to analyze "live" data and create visual reports with no involvement of IT specialists in the car industry of the Republic of Kazakhstan. Among the advantages of the application is support for importing files of different formats, the possibility of mobile access, real-time data updates, and others.

\section{REFERENCES}

[1] Baranova, O. A., Samoilenko, P. I. \& Zhuzhzhalov, V. E. (2010). Building the methodological system of training in informatics of students of higher educational institutions. Nauchnye Issledovaniya v Obrazovanii, 1, 8-10.

[2] Bogdanova, S. V., Kozel, I. V., Ermolina, L. V. \& Litvinova, T. N. (2016). Management of small innovational enterprise under the conditions of global competition: Possibilities and threats. European Research Studies Journal, 19 (2), 268-275.

[3] Chirkov, S. V. (2013). Technology of formation of the information culture of students of economics during the studying the informatics in higher educational institution. Vestnik Novosibirskogo Gosudarstvennogo Pedagogicheskogo Universiteta, 1(11), 64-73. 
[4] Danakin, N. S., Fomin, V. N. \& Gladkova, I. A. (2016). To the question about the organization of the social marketing service of the university. International Journal of Pharmacy and Technology, 8(4), 2469324698.

[5] Degtyareva, L. V. \& Semenyachenko, Yu. A. (2016). Training of bachelors of business informatics in solving the practical problems of marketing. Vestnik Rossiyskogo Universiteta Druzhby Narodov, series "Informatizatsiya Obrazovaniya", 1, 15-27.

[6] Gayurov, Kh. Sh. \& Vokhidova, Z. R. (2013). Methodology of teaching informatics to the students of economics on the basis of object-oriented approach. Vestnik Tadzhikskogo Gosudarstvennogo Universiteta Prava, Biznesa i Politiki, series "Gumanitarnye Nauki”, 4(56), 305-309.

[7] Guseva, E. N., Efimova, I. Yu. \& Varfolomeeva, T. N. (2019). Methodology of formation the skills of simulation in IT specialists. Otkrytoe Obrazovanie, 23(1), 4-13.

[8] Helfert, M. (2011). Characteristics of information systems and business informatics study programs. Informatics in Education, 10(1), 13-36.

[9] Hynek, J. A. (2018). Proceedings from 28th European Association for Education in Electrical and Information Engineering Annual Conference (EAEEIE): The Role of Logic Programming in ICT Specialists Curricula. Menntasetrio vio Laekinn, Hafnarfjordur, Iceland, pp. 1-9.

[10] Karyakin, V. P. \& Savelyeva, E. A. (2011). New information technologies and education. Vestnik KazNTU.

[11] Kelchevskaya, N. R. (2010). Analysis of the financial and economic activity of the state higher education institution as a basis of innovative solutions and programs. Universitetskoe Upravlenie: Praktika $i$ Analiz, 4(15).

[12] Kirillova, O. A. (2014). To the question of using the automated educational systems. Pedagogika $i$ Psikhologiya Obrazovaniya, 3, 43-47.

[13] Kolchina, V. V. (2017). Formation of readiness of a manager to the innovative-entrepreneurial activity as a pedagogical problem. Professionalnoe Obrazovanie $i$ Rynok Truda, 3, 28-34.

[14] Konina, O. V. \& Nanetadze, E. D. (2019). Managing a modern university: The role of business processes in the structure of establishments of higher professional education. Advances in Intelligent Systems and Computing, 726, 1053-10595.

[15] Lobok, A. M. (2008). The question of innovative activity in explication to the problematic field of educational program. Munitsipalnoye Obrazovaniye, 1, 6-10.
[16] McAdam, M., Miller, K. \& McAdam, R. (2017). University business models in disequilibrium engaging industry and end users within university technology transfer processes. $R$ and $D$ Management, 47(3), 458-472.

[17] Menyaev, M. F. (2003). Information technologies for organization management. Moscow: Omega-L.

[18] Message of the President of the Republic of Kazakhstan N. A. Nazarbayev "The Third Modernization of Kazakhstan: Global Competitiveness", Astana, Egemen Kazakhstan, January 31, 2017.

[19] Nikitina, N. I. \& Romanova, E. Yu. (2013). Pedagogical technologies for formation in the higher education institution the professional and mathematical culture of specialists in the field of business informatics. Istoricheskaya $i$ SotsialnoObrazovatelnaya mysl, 2, 84-89.

[20] Ryabukhina, E. A. \& Gushchina, O. A. (2012). System of teaching the informatics in the context of the project management theory. Integratsiya Obrazovaniya, 3, 3136.

[21] Sen, O. A. (2011). Formation the informational competences during the physics and informatics classes. Vestnik Novosibirskogo Gosudarstvennogo Universiteta, 1, 52-55.

[22] Tikhomirova, V. P. \& Khoroshilova, A. V. (2006). Introduction to the information business. Moscow: Finansy i Statistika.

[23] Verbitskiy, A. A. (1991). Active training in higher school: Contextual approach. Moscow: Vysshaya Shkola

[24] Kintonova, A.Z., Yermaganbetova, M.A., Abildinovaa, G.M., Ospanova N.N., Abdugulova, Z.K., Glazyrina, N.S. Optimization of business processes based on the supply chain management in an accounting department//International Journal of Supply Chain Management. Volume 8, Issue 3, 2019, pp. 369-379

[25] Yasenev, V. N. (2007). Automated information systems in economy. Nizhniy Novgorod: NNGU.

[26] Zinina, L. I. \& Petrova, E. S. (2012). Problems of development of new educational area "Business informatics". Integratsiya Obrazovaniya, 4, 31-46.

[27] Zolotaya, I. G. (2010). Formation of readiness of a teacher to the innovative activity in post-graduate period. Vestnik Chelyabinskogo Gosudarstvennogo Pedagogicheskogo Universiteta, 2, 103-109. 